\title{
The menopausal experience among indigenous women of Sarawak, Malaysia
}

\author{
S. A. R. Syed Alwi, P. Y. Lee, I. Awi, P. S. Mallik and M. N. Md Haizal*
}

Faculty of Medicine and Health Sciences, Universiti Malaysia Sarawak, Kuching; "Department of Obstetrics and Gynecology, Cyberjaya University College of Medical Sciences, Cyberjaya, Malaysia

Key words: MENOPAUSAL SYMPTOMS, MENOPAUSE-SPECIFIC QUALITY OF LIFE QUESTIONNAIRE, INDIGENOUS WOMEN, SARAWAK, MALAYSIA

\begin{abstract}
Objectives To document the common menopausal symptoms and quality of life in indigenous women of Sarawak in Malaysia.

Methods A face-to-face interview using the Menopause-specific Quality of Life questionnaire was conducted with 276 indigenous Sarawakian women aged 40-65 years to determine the mean age of menopause and common symptoms (divided into vasomotor, psychosocial, physical and sexual domains) associated with menopause.

Results The mean age at menopause of postmenopausal women was $50.78 \pm 2.47$ years (range 47.3-58.2 years). The most common symptoms reported were aching in muscles and joints $(82.6 \%)$, lack of energy $(77.5 \%)$ and low backache $(77.2 \%)$. The typical menopausal symptoms of hot flushes, night sweats, sweating and vaginal dryness were experienced by $42.4 \%, 34.8 \%, 29.7 \%$ and $49.3 \%$, respectively of the women studied. Perimenopausal women $(n=114)$ experienced the most physical and psychosocial symptoms, while postmenopausal women $(n=102)$ experienced most sexual symptoms. Perimenopausal and postmenopausal women were reported to suffer more than premenopausal women $(p<0.001)$ within the four domains of symptoms (vasomotor, psychosocial, physical and sexual).

Conclusions The menopausal symptoms in this study correspond to those in other studies on Asian women but the prevalence of typical and classical menopausal symptoms was lower compared to studies on Caucasian women. The perimenopausal women had the most significant decrease in quality of life, followed by postmenopausal women and premenopausal women. Vasomotor symptoms had a predominant influence on the quality of life.
\end{abstract}

\section{INTRODUCTION}

Although menopause is a normal physiological change experienced by most middle-aged women, it has its own health implications. Some women will experience menopausal symptoms that can be

severe enough to affect their normal daily activities and quality of life; this also has chronic long-term implications for their health. The majority of women are not aware of the changes 